\title{
UM ESTUDO SOBRE O SISTEMA CONSTRUTIVO SUSTENTÁVEL DE GESSO ACARTONADO: DRYWALL
}

Manoella Soares Barbosa Graduanda em Engenharia pelo Centro Universitário Augusto Motta (UNISUAM), RJ, Brasil manoellabarbosa@ymail.com

Suzana Vieira Américo Graduanda em Engenharia pelo Centro Universitário Augusto Motta (UNISUAM), RJ, Brasil suzana_americo@yahoo.com.br

Everton Rangel Bispo Doutor em ciências, engenharia edocente do Curso de Engenharia Civil, da UNISUAM, RJ

Jose Roberto Moreira Ribeiro Gonçalves Mestre em Engenharia Agrícola e Ambiental pela UFRRJ Professor do Centro Universitário Augusto Motta (UNISUAM), RJ, Brasil. joserobertoverde@gmail.com

\section{RESUMO}

O presente artigo apresenta um estudo sobre o sistema construtivo sustentável drywall, que é uma alternativa para a fase de vedação verticais e acústica de ambientes, veio para implementar com novas tecnologias na construção prática, onde possui raízes no gesso natural e aditivos. $O$ drywall é caracterizado como um sistema de arquitetura que permite ser elaborado de forma limpa, por utilizar pouca água e sem uso de outros materiais, ou seja, é uma construção seca. O Sistema é muito utilizado no exterior, porém vem crescendo a cada dia no Brasil. Além disso, tem boa resistência e podem adaptar portas, janelas, entre outros. Todavia, alguns cuidados adicionais devem ser tomados, como por exemplo: o dimensionamento tem que estar adequado ao pé-direito da edificação, a espessura das placas condicionada a mesma questão e também às cargas a que o sistema que estará submetido (instalação de bancadas de pedra, móveis, etc.). Por meio de pesquisas bibliográfica e documental, este artigo apresenta a origem, as vantagens e desvantagens, o projeto detalhado, o impacto econômico e ambiental do sistema drywall. Também apresenta alguns exemplos de melhores locais a serem aplicados o sistema de drywall, e por fim, mostrar um comparativo entre outra forma de vedação de um espaço, como blocos de alvenaria, mostrando os benefícios e os impactos, além da abordagemdos custos desses sistemas.

Palavras-chave: Tecnologias; Sustentável; Drywall.

\section{A STUDY ON THE SUSTAINABLE CONSTRUCTION SYSTEM OF PLASTERED PLASTER: DRYWALL}

\begin{abstract}
This article presents a studyon the constructive and sustainable drywall system, which is an alternative to the vertical sealing and acoustic phase of environments, came to implement with new technologies in practical construction, where it has roots in natural gypsum and additives. The drywall is characterized as an architecture system that allows to be elaborated of clean form, to use little water and without use of other materials, completing a dry construction. The system is widely used abroad, but has been growing every day in Brazil, has good resistance and can adapt doors,
\end{abstract}


windows, among others. However, some additional care must be taken, among them: the dimensioning has to be adequate to the right of the building, the thickness of the plates conditioned the same question and also to the loads to which the system that will be submitted (installation of stone benches, furniture, etc.). Through a bibliographical and documentary research, this article presents the origin, the advantages and disadvantages, the detailed design, the economic and environmental impact of the drywall system. Also, it presents some examples of better places to be applied the system of drywall, and, finally, to show a comparison between another form of sealing of a space, like masonry blocks, showing the benefits and the impacts, besides the approach of the costs of these systems.

Keywords: Technologies; Sustainable; Drywall

\section{INTRODUÇÃO}

O setor da construção é um dos mais importantes, não só no país, mundialmente movimenta a economia. Tem uma grande geração de empregos diretos e indiretos, traz grande desenvolvimento para as cidades em todos os ramos, transporte, infraestrutura, urbanização, habitação, entre outros.

O ramo habitacional é o maior segmento dentro da construção civil, o que gera maior número de vagas de trabalho, que recebem maiores investimentos, e logo o que gera mais resíduo, consome maior número de recursos naturais. Hoje em dia as construções devem não só ter um excelente projeto, visando racionalizar a execução, mão de obra, tempo e custo, mas deve ser pensada em função do meio ambiente.

Como realizar de forma mais sustentável esses projetos, utilizando recursos de fontes renováveis, gerando menos resíduos nos canteiros de obras e menos gases poluentes? (FLEURY, 2014).

Em um mercado competitivo como o da construção civil brasileira, identificar produtos e sistemas construtivos realmente inovadores não é uma tarefa fácil. Todo ano, construtores e projetistas são apresentados a uma variedade de soluções criadas para otimizar processos, reduzir custos ou melhorar a quantidade dos projetos de edificações e de infraestrutura (FARIA, 2014).

Com uma instalação limpa, facilidade na execução de reparos, uma maior flexibilidade no acabamento e um melhor desempenho acústico e térmico o sistema drywall vem tendo um crescimento significativo ao longo dos últimos anos no Brasil, saltando de 12 milhões de metros quadrados instalados em 2003 para cerca de 50 milhões de metros quadrados instalados em 2013 (CIOCCHI, 2003; ASSOCIAÇÃO BRASILEIRA DE DRYWALL, 2015). 
As paredes de Drywall vêm ganhando espaço no Brasil, na medida em que métodos construtivos mais rápidos e industrializados se tornam cada vez mais necessários nos canteiros de obras (MARIANE, 2012).

No mercado já é possível encontrar formas de se adequar as obras de maneiras sustentáveis. O Brasil, como um país em desenvolvimento, um país emergente, ainda está muito aquém dos países considerados de primeiro mundo, nessas construções. Em alguns lugares o maior número de construções habitacionais já faz o uso de materiais assim, em outros até exigem. Nos Estados Unidos, por exemplo, o sistema construtivo drywall é o mais utilizado. Patenteado por eles em 1894, tem relação com dois grandes incêndios que ocorreram em Chicago e Nova York. Após a tragédia era preciso pensar em materiais mais resistente a fogo e às intempéries para reconstruir as cidades, já que antes era utilizado materiais facilmente inflamáveis, madeira principalmente. 0 sistema de drywall veio para revolucionar o ramo da construção, pois tinha as exigências necessárias e era possível reconstruir com eficiência e rapidez (KNAUF, 2018).

As paredes de gesso acartonado podem ser definidas como um sistema constituído por perfis de chapas de aço zincado leves e placas de gesso acartonado de alta resistência mecânica e acústica, fixadas por meio de parafusos especiais com tratamento de juntas e arestas. A formação desses elementos resulta em um conjunto com espessura por exemplo de $9 \mathrm{~cm}$ (BERNARDI, 2014).

Apesar do avanço, apenas $20 \%$ das chapas produzidas eram empregados como divisórias em ambientes comerciais, o restante era utilizada como forros (TAGLIABOA, 2011).

Nesse artigo iremos demonstrar os estudos feitos de comparação das construções feitas de drywall com as construções de alvenaria, e seus benefícios e custos. $\mathrm{O}$ objetivo do presente artigo é apresentar os benefícios do uso de drywall nas edificações residenciais, visando fechamento e divisórias verticais em obras mais rápidas e sustentáveis, de forma inteligente.

\section{METODOLOGIA}

O estudo em questão será embasado em informações obtidas de sites, artigos, dissertações de mestrado, fabricantes das placas de gesso acartonado e livros. Primeiramente, será apresentada uma breve análise histórica sobre o drywall, bem como o início da sua utilização no Brasil e no exterior através de revisões bibliográficas e pesquisas. Posteriormente, serão discutidos métodos construtivos, vantagens e desvantagens de sua utilização, necessidades de execução de obras desse tipo. Em seguida apresentação dos estudos de caso relatando uma patologia e um paralelo entre este tipo de execução em relação à alvenaria de blocos cerâmicos. Finalmente serão apresentados 
os dados obtidos e uma sucinta conclusão sobre a utilização e viabilidade de custos do sistema de Drywall com placas de gesso acartonado.

\section{DESENVOLVIMENTO}

\subsection{Referencial Histórico}

O início da história do drywall tem mais de 100 anos, no início era conhecido como SackettBoard e era composto por uma chapa e de duas a três camadas bem finas de gesso, se a folha de feltro o que as separavam e o conjunto era revestido por cartão (FERSAN, 2018). Um tempo depois, um layout mais atual tomou a forma da capa, proporcionando uma configuração de apenas um miolo, sendo isentas as divisões que no início eram necessárias (FERSAN, 2018)

Com o passar do tempo, instalou-se a fábrica pioneira no sistema construtivo de gesso acartonado. Instalada em Nova Jersey nos Estados Unidos e logo a expansão do produto no mercado fez com que todo o país dos EUA e o Canadá adotassem o mais novo método (KNAUF, 2018).

Em 1970, foi instalada no Nordeste a primeira fábrica de gesso acartonado para drywall no Brasil. Este feito ocorreu graças à iniciativa de Roberto de Campos Guimarães que fundou a Gypsum, em Petrolina, Pernanbuco e, através da fábrica, foram originadas diversas oportunidades de empregos na área de sistemas de drywall instalado no país.

A aprovação do sistema pelos usuários fez com que diversos edifícios, casas e conjuntos habitacionais (KNAUF, 2018).

A história do drywall chegou ao Brasil produzindosoluções práticas e inteligentes na arquitetura como, por exemplo, na utilização de forros, revestimentos e divisões práticas para construções em geral (KNAUF, 2018).

Apesar da utilização crescente do Drywall, há uma carência no nosso país sobre o conhecimento dessa tecnologia construtiva, a difusão de conhecimento técnico busca principalmente desmitificar a crença que as paredes de gesso são frágeis e vencer o preconceito dos consumidores de uma técnica já consolidada em países desenvolvidos (NUNES, 2015).

A placa de gesso acartonado, além de prática, garante um menor custo nas em construções em geral, uma vez que reduzido o volume de mão de obra, tem-se a redução do tempo de trabalho e menor desperdício de materiais já que é uma construção a seco. O drywall é testado e avaliado pelos índices especificados por institutos internacionais.

A chapa além de resistente ao fogo garante o isolamento acústico e térmico da edificação e também é imune ao ataque de insetos, fungos e outros agentes externos do ambiente. O drywall é 
bem mais leve que outros materiais convencionais para vedação que acabam tendo a mesma finalidade e, além disso, a placa de gesso é resistente mecanicamente, absolutamente estável e flexível (KNAUF, 2018).

Com essa configuração mais rápida, eficaz e inteligente, o drywall possui qualidades que se adequam aos ambientes e fornecem resultados mais limpos em aplicações, pois a mesma pode ser fixada e removida. Permite também fácil aplicação de tubulações e acesso a elas. $O$ peso das paredes internas também influencia na escolha do sistema, poisgeram uma diminuição de carga nas estruturas devido a leveza e menor espessura das placas; o sistema ainda garante melhor manuseio e rapidez na execução e entrega do serviço; o revestimento substitui em apenas uma aplicação o reboco, o chapisco e a massa fina. E também obtém como resultado final um acabamento uniforme e sem emendas na superfície, unindo tecnologia e simplicidade para gerar soluções (KNAUF, 2018).

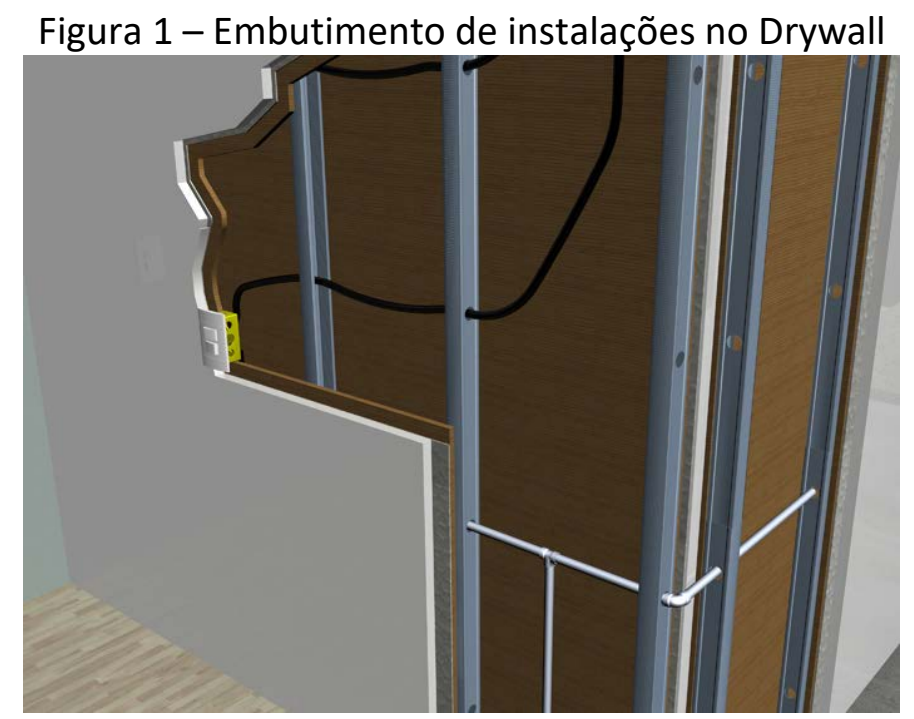

Fonte: (Atacadão Forros)

Atual, a construção a seco usa recursos construtivos nos quais não há aplicação de água como material na execução. Os métodos mais relacionados ao não uso da água são o Steel Frame e o Drywall. Este é um sistema de vedação interna, sem função estrutural; Aquele, é composto por perfis metálicos leves com função estrutural revestidas com placas cimentícias, tiras de madeira ou placas de gesso. A principal vantagem da construção a seco em relação aos métodos convencionais, é que, por utilizarem insumos pré-fabricados eles podem ser considerados sistemas de montagem, onde suas peças são encaixadas e logo fixadas. Dessa forma, tem-se uma execução rápida se comparada a outros métodos executivos. A baixa quantidade de desperdício também é uma significativa vantagem desse tipo de construção, e consequentemente há a redução de entulho, mantendo assim um ambiente de obra limpo e com menor produção de resíduos, diminuindo os descartes destes no meio-ambiente (FLEURY, 2014). 


\subsection{Revisão de literatura}

O ser humano usa vedações verticais para proteção desde as primeiras edificações construídas (BERNARDI, 2014).

As formas de vedações internas nas construções foram se firmando através do melhoramento com materiais que oferecem melhor aproveitamento estrutural, acústico e térmico.

Com a criação da norma de desempenho (ABNT NBR15575) em 2013, as vedações passaram a ser ainda mais relevantes como opção na construção civil, pelo fato de terem sido impostos algumas exigências que garantiriam maior conforto e segurança aos usuários. O sistema de vedações verticais é classificado em vista do ambiente, podendo ser vedação interna e vedação externa (SABBATINI et al., 2003).

Se tradando das classificações, a vertical interna ainda pode ser divididaem duas funções: a função estrutural, através dos blocos estruturais e a vedação auto-portante, sendo não estrutural e é responsável apenas pela vedação ou divisão dos ambientes.

De modo geral, as vedações também são divididas quanto a capacidade de se mover, sendo elas: fixadas, desmontáveis e móveis. As fixas não permitem ser realocadas pela impossibilidade de reutilização depois de prontas, um exemplo é a alvenaria. As desmontáveis podem ser realocadas através da desmontagem e remontagem, como as vedações com drywall. As móveis são as opções de fechamento que podem ser movimentadas sem que sejam desmontadas, nesse caso pode-se citar os biombos (SABBATINI, 2003).

A NBR 11685/1990 classifica as vedações em dois grupos: leves, para as possuintes de densidade superficial de até $60 \mathrm{~kg} / \mathrm{m}^{2}$ e as pesadas são as que possuem a densidade superficial maior que $60 \mathrm{~kg} / \mathrm{m}^{2}$.

A norma NBR 15575 determina três níveis de classificação para desempenho de elementos de um edifício, são eles: mínimo, intermediário e superior; abrangendo os itens gerais, estrutura, pisos, vedações verticais, cobertura e sistemas hidráulicos. Nas construções de alvenaria é mais difícil atingir todos os critérios estabelecidos pelas normas que a regem, por isso haverá um crescimento desse sistema a seco, futuramente, no mercado da construção que é o tipo de vedação vertical que mais obedece às exigências da NBR 15575/2013 (PLACO 2014).

\subsection{Alvenaria}


Para melhor entendimento dos próximos tópicos, vale enaltecer algumas informações construtivas cruciais sobre alvenaria, sistema tão utilizado na construção e ainda classificado por muitos como sendo o ideal. A alvenaria éformada pela junção de blocos ou tijolos através da utilização de argamassas e revestida com materiais como a própria argamassa ou gesso. A alvenaria pode ser separada em dois tipos, alvenaria estrutural e alvenaria de vedação simples. A alvenaria estrutural não só tem a função de fechamento, mas também recebem cargas das estruturas. A segunda é utilizada apenas para vedação simples, interna ou externa.

\subsection{Comparativos de Alvenaria x Drywall}

Quando se trata de escolher entre paredes em drywall e paredes convencionais (em alvenaria de tijolos), muitas profissionais ainda encontram dúvidas quanto às vantagens e desvantagens do atual sistema de construção a seco. Dessa forma, seguem algumas informações relevantes sobre o sistema, comparando-o com a alvenaria.

3.4.1 Vantagens do sistema de drywall:

a. Diminuição na quantidade de materiais que devem ser transportados até o local de instalação e simples manuseio;

b. Menos mão de obra, mais produtividade;

c. Layout adaptável pode-se trabalhar com paredes tanto curvadas quanto mais uniformes;

d. Não é necessário quebra da parede para colocação de instalações;

e. A manutenção de instalações se torna muito mais fácil;

f. O ambiente ganha área útil devido pequena espessura das placas (geralmente $12,5 \mathrm{~mm}$ de espessura; $1,20 \mathrm{~mm}$ de largura e altura igual ao pé direito do pavimento)

g. Local da obra limpo e com menor geração de resíduos, sendo os gerados, recicláveis;

h. Resíduos recicláveis;

i. Diminuição do peso que atuante na estrutura;

j. Melhor no acabamento.

Apesar de todas as vantagens do drywall listadas, as que mais se sobressaem quando comparadas a alvenaria convencional está ligada ao tempo de execuçãoe o custo final dessas 
vedações verticais a seco. A redução do tempo pode chegar a $60 \%$ do tempo gasto em uma parede de alvenaria (G1 apud REIS, 2012).

Figura 2 - Cenário construtivo com o sistema Drywall

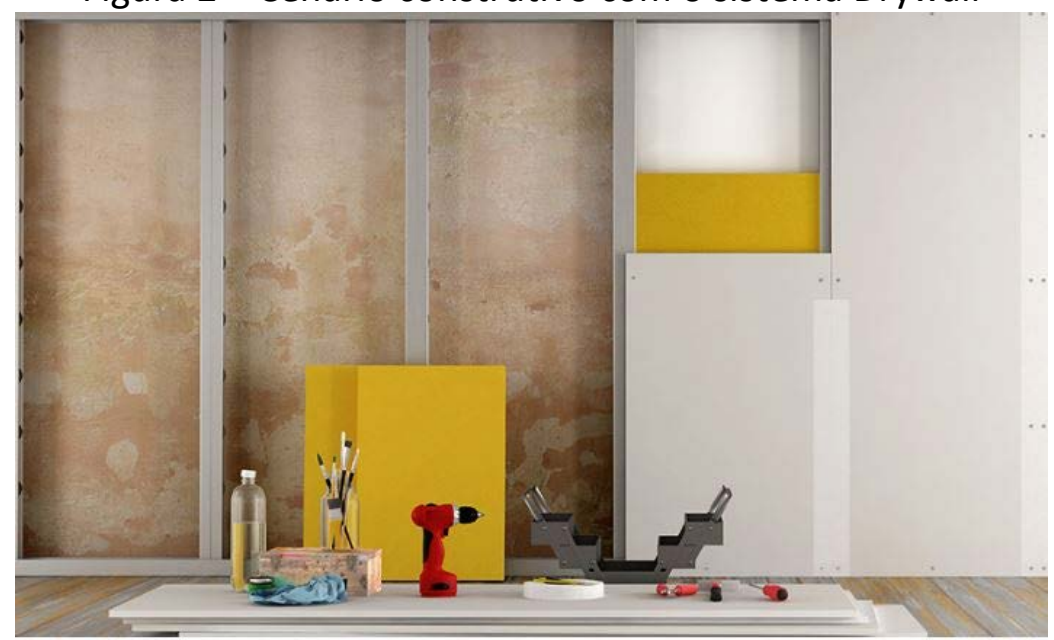

Fonte: (Weg - tomadas e interruptores, 2019)

Figura 3 - Composição da vedação

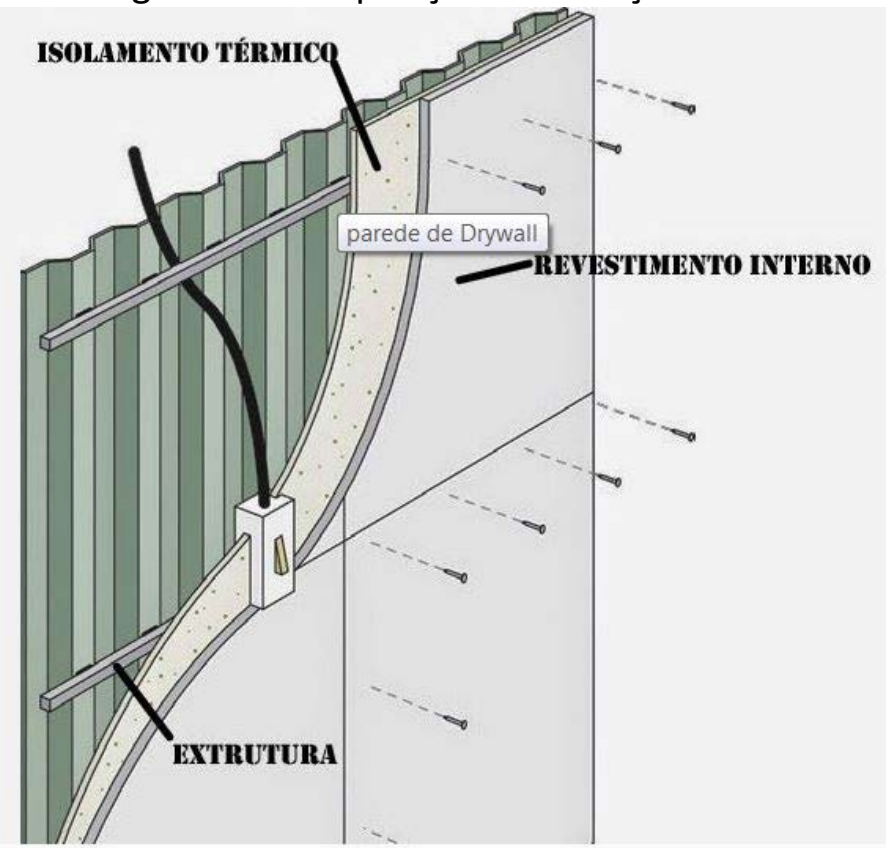

Fonte: Obra Rio, 2017.

Já o valor final da obra, reduz-se significativamente com a utilização das placas de gesso acartonado devido a redução de pesos impostos na estrutura, redução do custo e de mão de obra.

A parede feita de placa de gesso resulta em uma diminuição de cerca de $10 \%$ no consumo de materiais como fôrmas, aço e concreto para execução das estruturas (FERREIRA, 2012). Logo, o drywall permite estruturas e fundações mais esbeltas e consequentemente, uma redução no custo final da obra (FERREIRA, 2012); (G1 apud REIS, 2012). 


\subsubsection{Desvantagens do sistema de Drywall}

O sistema de drywall apesar de obedecer às normas de desempenho ainda não é totalmente aceito como uma forma confiável por muitos usuários que não conhecem o produto, inclusive a norma de desempenho. Porém, os consumidores e construtores ainda possuem um certo preconceito, o que se torna uma resistência para empresas adotarem esse método executivo no mercado brasileiro (PLACO, 2014).

a. Ainda há muito preconceito dos clientes, levando-os ao uso de blocos cerâmicos;

b. Sua instalação deve ser através de mão de obra especializada;

c. Para resistir à ambientes úmidos, a escolha da placa é o que torna viável ou não. Uma atenção especial também deve ser dada ao distanciamento das extremidades com laje de piso e cobertura;

d. Dificuldade na fixação de cargas, objetos pendurados devem ficar bem próximos dos reforços;

e. A presença de juntas de dilatação é crucial na interface com as lajes, pois a placa possui uma dilatação térmica com dimensões diferentes do croncreto;

f. Geração de resíduos nocivos.

\subsubsection{Desempenho Acústico}

A capacidade de proteção acústica é uma das partes mais importantes quando se trata de vedações verticais pois, quando esta é mau dimensionada, a passagem de sonoridade e ruído de outros ambientes ou do meio externo geram incômodos aos usuários (NETO et al., 2010).

Os blocos de $14 \mathrm{~cm}$ com revestimentos de argamassa apresentam isolação acústica de $40 \mathrm{~dB}$ (THOMAZ et al., 2009). Apesar da menor densidade das placas de gesso acartonado, este também é um bom isolante acústico e conseguem atingir um elevado nível de proteção contra ruídos (THOMAZ et al., 2009).

Porém, sua viabilidade acústica está ligada ao modo de instalação e aos elementos utilizados nesta. Adotando-se uma parede com placa simples de $12,50 \mathrm{~mm}$, estas com fixadores de aço de 60 a $70 \mathrm{~mm}$, tem-se um isolamento padrão com cerca de $37 \mathrm{~dB}$; Se adotadas paredes com placas duplas, ou seja, 4 placas de 12,5mm e a utilização de lã mineral, pode-se chegar a um isolamento de $50 \mathrm{~dB}$ (LUCA, 2013). 


\subsubsection{Peso na estrutura}

As paredes simples de drywall, possuindo duas placas, exercem sobre a estrutura um peso de $20 \mathrm{~kg} / \mathrm{m}^{2}$, as paredes duplas com isolação acústica pesam $37 \mathrm{~kg} / \mathrm{m}^{2}$ (PLACO, 2014). Segundo uma fabricante de blocos cerâmicos, só os blocos com furo exercem peso de quase $80 \mathrm{~kg} / \mathrm{m}^{2}$ (CERAMICAS ERMIDAS, 2014), incluindo a argamassa com uma densidade de 1.400 a $1.800 \mathrm{~kg} / \mathrm{m}^{3}$ soma-se um valor que pode chegar até a $27 \mathrm{~kg} / \mathrm{m}^{2}$ a essa carga dos tijolos (MATRIX, 2014).

\subsubsection{Composições e custos}

Em 2014, numa obra no estado de Brasília, foram orçados em planilhas, com base na Tabela de Composições de Preços para Orçamentos - TCPO, o preço final de duas opções de vedação: Alvenaria e Drywall. Para alvenaria, foi realizada uma composição com blocos cerâmicos de $11,5 \mathrm{~cm}$ x $19 \mathrm{~cm} \times 19 \mathrm{~cm}$, com furos, para as vedações internas (Tabela 1).

Tabela 1 - Composição de custo para parede de alvenaria

\begin{tabular}{|c|c|c|c|c|c|c|}
\hline \multicolumn{7}{|c|}{ Composição de custo - Alvenaria 11,5 - Paredes internas } \\
\hline Serviço & $\begin{array}{c}\text { Quantidade } \\
\text { orçada } \\
\left(\mathrm{m}^{2}\right)\end{array}$ & Insumo & Consumo/m $\mathrm{m}^{2}$ & Consumo total & $\begin{array}{l}\text { Preço un } \\
\text { (R\$) }\end{array}$ & $\begin{array}{c}\text { Custo total } \\
\text { (R\$) }\end{array}$ \\
\hline $\begin{array}{c}\text { Alvenaria } \\
\text { de }\end{array}$ & $11.201,25$ & Pedreiro & $1,05 \mathrm{~h}$ & $11761,3125 \mathrm{~h}$ & 13,14 & \multirow{4}{*}{$408.655,20$} \\
\hline blocos & $11.201,25$ & Servente & $0,77 \mathrm{~h}$ & $8624,9625 \mathrm{~h}$ & 8,48 & \\
\hline cerâmicos & $11.201,25$ & $\begin{array}{c}\text { Argamassa para } \\
\text { assentamento }\end{array}$ & $9,62 \mathrm{~kg}$ & $107756,025 \mathrm{~kg}$ & 0,22 & \\
\hline $11,5 \times 19 \times 19$ & $11.201,25$ & Blocos $11,5 \times 19 \times 19$ & 27 un & 302433,75 un & 0,52 & \\
\hline
\end{tabular}

Fonte: Construtora Placo

A primeira para paredes de divisa interna das casas, compostas por duas chapas de $12,5 \mathrm{~mm}$ fixadas em guias de $70 \mathrm{~mm}$ e montantes espaçados em $600 \mathrm{~mm}$. Já a outra composição, foi feita para paredes de germinação. Nessas, além das chapas de duas chapas 12,5 mm incluiu-se mais duas chapas, ou seja, quatro placas de gesso e a lã de vidro (Tabela 2). 
Tabela 2 - Composição de custos drywall

\begin{tabular}{|c|c|c|c|c|c|c|}
\hline \multicolumn{7}{|c|}{ Composição de custo - Drywaal 95/70/600 mm ST+ST ou ST+RU ou RU+RU - Paredes internas } \\
\hline Serviço & $\begin{array}{c}\text { Quantidade } \\
\text { orçada }\end{array}$ & Insumo & Consumo/m $\mathrm{m}^{2}$ & Consumo total & Preço un & Custo total \\
\hline \multirow{8}{*}{$\begin{array}{c}\text { Drywall } \\
90 / 70 / 600 \mathrm{~mm}\end{array}$} & $11201,25 \mathrm{~m}^{2}$ & Mão de obra & $0,6 \mathrm{~h}$ & $6720,75 \mathrm{~h}$ & $\mathrm{R} \$ 31,42$ & \multirow{8}{*}{$\begin{array}{c}\mathrm{R} \$ \\
579.755,42\end{array}$} \\
\hline & $11201,25 \mathrm{~m}^{2}$ & Placa & $2,06 \mathrm{~m}^{2}$ & $23704,575 \mathrm{~m}^{2}$ & $\mathrm{R} \$ 10,60$ & \\
\hline & $11201,25 \mathrm{~m}^{2}$ & Massa junta & $0,87 \mathrm{~kg}$ & $9745,0875 \mathrm{~kg}$ & $\mathrm{R} \$ 1,34$ & \\
\hline & $11201,25 \mathrm{~m}^{2}$ & Gula & $0,8 \mathrm{~m}$ & $8961 \mathrm{~m}$ & $\mathrm{R} \$ 2,45$ & \\
\hline & $11201,25 \mathrm{~m}^{2}$ & Montante & $1,84 \mathrm{~m}$ & $20610,3 \mathrm{~m}$ & $\mathrm{R} \$ 2,41$ & \\
\hline & $11201,25 \mathrm{~m}^{2}$ & $\begin{array}{c}\text { Fita } \mathrm{p} \text { isolamento } \\
\text { acustico }\end{array}$ & $1,83 \mathrm{~m}$ & $20498,2875 \mathrm{~m}$ & $\mathrm{R} \$ 1,53$ & \\
\hline & $11201,25 \mathrm{~m}^{2}$ & Fita $\mathrm{p}$ junta & $3 \mathrm{~m}$ & $33603,75 \mathrm{~m}$ & $R \$ 0,09$ & \\
\hline & $11201,25 \mathrm{~m}^{2}$ & Parafuso & 22 un & 246427,5 un & $\mathrm{R} \$ 0,02$ & \\
\hline
\end{tabular}

Fonte: (Construtora Placo)

\subsubsection{Custos totais}

Dessa forma, obteve-se o valor final $\mathrm{R} \$ 579.755,42$ para o sistema de drywall. Para a alvenaria com revestimento na área interna, o valor total de orçamento é de $R \$ 408.655,20$, entretanto, tem-se a soma do revestimento argamassado, chegando $\mathrm{R} \$ 348.709,96$. Logo, o custo total final para as paredes internas com drywall saíram bem mais em conta se comparado à alvenaria (Tabela 3).

Tabela 3 - Comparativo de custos

\begin{tabular}{|c|c|}
\hline \multicolumn{2}{|c|}{ Comparativo de custos totais } \\
\hline Sistema & Custo total \\
\hline Drywall & $\mathrm{R} \$ 579.755,42$ \\
Alvenaria + & \\
Revestimento & \\
Argamassado & $\mathrm{R} \$ 757.365,16$ \\
\hline
\end{tabular}

3.5 Análises de resultados comparativos

Foi visto anteriormente as vantagens do método de vedação de drywall, estas ainda podem ser divididas em duas categorias. A primeira tem a ver com os pontos que são benéficos para o cliente, são as vantagens ligadas com o consumidor final e são elas: a flexibilidade no layout, a facilidade na manutenção de instalações e o ganho de área útil (PLACO,2014). 
A segunda categoria visa os benefícios da construtora, são vantagens que impactam diretamente na construção e/ou nos custos. Entre os benefícios para a construtora, o mais relevante é disparado, o aumento da produtividade. A redução de cerca de metade do tempo para a execução de vedações gera grandes retornos financeiro para a construtora se levado em consideração o custo final (PLACO,2014).

Assim como as vantagens, as desvantagens do sistema de drywall podem ser dividas nos mesmos dois grupos mas que, de certa forma, são dependentes: desvantagem para o consumidor e desvantagem para construtoras. Dentre as desvantagens mencionadas no primeiro grupo, as mais relevantes são o efeito knockknock e o cuidado que se deve ter para fixar cargas. Consequentemente, ambas resultam na principal desvantagem para construtora: a rejeição do mercado. Em outros países, esses empecilhos não atrapalham na escolha do sistema construtivo de gesso, mas no Brasil, ainda não se tem esse pensamento, o que se torna um desafio para as empresas superarem dentro desse mercado (PLACO,2014).

\subsubsection{Análise do peso e acústica na estrutura e fundação}

Analisando as diferenças entre as cargas atuantes na estrutura, é perceptível que a carga de uma vedação feita com alvenaria é quase seis vezes superior a carga utilizada no sistema drywall. Assim, o uso das chapas de gesso garantem uma significativa redução no dimensionamento estrutural e, consequentemente, atingem as fundações.

Os resultados de acústica são referentes a índices de redução sonora ponderada, o ensaio foi feito em paredes de gesso acartonado pela ABRAGESSO, em 2014 e em alvenaria de cerâmica com revestimento de argamassa por NETO E BERTOLI, em 2010. O resultado entre os métodos comparativos teve uma diferença de $1 \mathrm{~dB}$, feitos para paredes divisórias de uma mesma unidade. Comparativos dos métodos escolhidos para paredes de divisas de uma mesma unidade tiveram diferença de $1 \mathrm{~dB}$. Entretanto, o resultado dos ensaios das vedações para divisão de unidades habitacionais tiveram uma grande diferença de $12 \mathrm{~dB}$.

Para paredes que separam ambientes de uma mesma unidade a NBR 15575-4 não é exigido desempenho acústico mínimo, porém, os dois tipos possuem resultados aproximados de isolação acústica nos ensaios. Todavia, para vedações entre unidades diferentes, há grande diferença nos índices de isolamento.

O uso do drywall com placa de gesso dupla e lã de vidro apresenta isolamento de $51 \mathrm{~dB}$, que é o nível intermediário especificado pela norma. Já a alvenaria de cerâmica atinge isolamento de 39 
$d B$, não chegando ao nível máximo que a norma exige que, pra esse tipo de parede é mínimo de 45 dB (PLACO,2014).

Sua versatilidade se estende nas diversas opções de revestimentos que podem ser aplicados, nas formas que podem ser executadas, como por exemplo, paredes em curva e também na possibilidade de ser desmontada, facilitando a mudança de layouts (GUIA PLACO, 2014).

\subsubsection{Conclusão da análise dos custos}

É visível que a economia gerada pelo uso do drywall é grande para este tipo de construção, levando em conta que são áreas de $200 \mathrm{~m}^{2}$ para cada apartamento da obra analisada. Por isso, o número de vedações entre unidades é baixo, dessa forma, se fosse analisado um orçamento desse mesmo sistema para outro tipo de empreendimento com menores dimensões e maior quantidade de unidade habitacional, tem-se uma metragem maior de paredes e o custo do drywall pode variar, já que para divisão entre unidades é necessário quatro placas de gesso e lã de vidro para obter umbom isolamento acústico (PLACO,2014).

Hoje, a disseminação do sistema Drywall no Brasil demonstra sua importância como solução alternativa à alvenaria, tendo a seu favor diversos benefícios, como por exemplo, a redução de material excedente, melhor relação custo-benefício e maior personalização dos projetos (KNAUF, 2014).

\section{CONSIDERAÇÕES FINAIS}

Analisando a chegada do drywall no Brasil, principalmente nos últimos tempos, vimos a sua evolução, onde alcançou uma consistência inovadora e inteligente, através de suas vantagens, ele vem garantindo cada vez mais sua visibilidade no mercado. O presente artigo mostrou que através da Norma 15575 -2013, as exigências que se atrelam a uma construção, devem ser analisadas detalhadamente.

Quando faz-se a comparação do gasto final em materiais e mão de obra , a opção do sistema de gesso apresentado pode chegar a $65 \%$ na economia de material e a $35 \%$ na economia de mão de obra. A execução de vedação interna com alvenaria não oferece bons resultados, fora o maior gasto de tempo de obra e desperdícios, acarretando em gastos demasiados.

Através dos dados de pesquisa, conclui-se que as vantagens obtidas pelo método construtivo do sistema de gesso acartonado beneficia vários aspectos, proporcionando mais espaço, limpeza, 
rapidez, sustentabilidade, entre outros, o mercado brasileiro a cada dia cresce buscando inovações para o ganho de tempo, além de ter como junção a qualidade do material, o sistema drywall atingi todas as expectativas esperadas, tornando-se um material disponível para construções de todos os tipos, como as obras pequenas à obras sofisticadas.

Apesar da perspectiva positiva, os produtores de gesso acartonado têm um árduo trabalho pela frente: derrubar o estigma de que o drywall é um produto caro e não oferece resistência e isolamento adequados. Com isso, espera-se que futuramente, através de inovações e melhoras no sistema, o mercado esteja mais confiante nesse tipo de construção a seco.

\section{REFERENCIAS}

Associação Brasileira de Normas Técnicas. ABNT NBR 15270-1. Componentes cerâmicos Parte 1: Blocos cerâmicos para alvenaria de vedação - Terminologia e requisitos. 2005

ABNT NBR 15575-1. Edificações habitacionais - Desempenho - Parte 1: Requisitos gerais. 2013

ABNT NBR 15575-4. Edificações habitacionais - Desempenho - Parte 4: Requisitos para os sistemas de vedações verticais internas e externas - SVVIE. 2013

ABRAGESSO - Associação Brasileira dos Fabricantes de Blocos e Chapas de Gesso. www.drywall.org.br - Acessado em: Novembro 2018.

ACARTONADO: A História do gesso acartonado. Disponível em: www.acartonadogesso.com.br/historiadogessoacartonado. Acesso em Novembro de 2018

ASSOCIAÇÃO BRASILEIRA DO DRYWALL: Para Qualidade Acústica. Disponível em: www.proacustica.org.br. Acesso: em Abr 2018.

BERNARDI, VINICIUS BATISTA. Análise do Método Construtivo de Vedação Vertical Interna em Drywall em Comparação com a Alvenaria. 2014. 41 p. - Relatório de estágio - Universidade do Planando Catarinense, Lages (SC), 2014.

CERÂMICA ERMIDA - www.ceramicaermida.com.br - Acessada em: Setembro 2014.

ClOCCHI, L. Use corretamente o Gesso Acartonado. São Paulo, SP: Pini, 2003. Disponível em: Acessado em: 15 set. 2015

CONSTRUTORA PLACO: Sistema Construtivo em Drywall. Disponível em: https://www.placo.com.br/. Acesso em: Novembro de 2018

CONSTRUFACILIRJ. PLACA DE GESSO ACARTONADO. Disponível em: http://construfacilrj.com.br/placas-de-gesso-liso-e-acartonado/. Acesso: em Maio 2018. 
DRYWALL - Associação Brasileira do drywall - http://www.drywall.org.br/imprensa- Acessado em: Novembro de 2018.

FARIA R., Revista Técjne, Ed. 208, julho, 2014. Prêmio Téchne de inovação Teconlógica na contrução civil destaca produtos e sistemas contrutivos inovadores. Disponivel em: http://techne.pini.com.br/engenharia-civil/208/premio-techne-de-inovacao-na-construcao-civildestaca-produtos-e-319298-1.aspx - Acessado em novembro 2018

FLEURY, L. E. - Análise das vedações verticais internas de Drywall e alvernaria de blocos cerâmicos com estudo de caso comparativo. Trabalho de Curso apresentado como um dos requisitos para a conclusão do curso de Engenharia Civil do UNICEUB - Centro Universitário de Brasília, 2014. Brasília, 2014.

FERREIRA, Romário. Revista Construção mercado. Noticia: Alvenaria de tijolos cerâmicos X drywall. Edição 136, editora PINI, 2012.

GYPSUM - Empresa grupo Etex. Disponível em: www.gypsum.com.br/pt-pt/nossa-empresa/salade-imprensa/release/gypsum-prepara-o-lancamento-da-maior-fabrica-de-drywall-da-america-dosul - Acessado em: Novembro de 2018.

GUIA PLACO- Soluções Construtivas 2014. Disponível em:. Acesso em 17 Setembro de 2018.

GYPSUM, Gypsum do nordeste. A gypsum tem muita história pra contar. Petrolina, 1999.

GYPSUM. GUIA DE ESPECIFICAÇÃO - RESIDÊNCIAS. 2012

HOLANDA, E. P. T. de. Novas tecnologias construtivas para produção de vedações verticais:diretrizes para o treinamento da mão de obra. São Paulo, 2003.

KNAUF - Manual de Instalação, Sistemas KnaufDrywall. 2014. Disponível em: Acesso em 17 Setembro de 2018.

LUCA, Carlos Roberto de. Desempenho acústico em sistemas drywall. 2a Edição, Associação Brasileira de Drywall, 2013.

MARIANE A. Execução de parede de drywall: Revista Mercado Construção, negócios de incorporação e construção, Ed. 134, Setembro, 2012: Disponível em:

<http://construcaomercado.pini.com.br/negocios-incorporacao-construcao/134/execucao-deparede-de-drywall-cotacao-deve-incluir-material-299138-1.aspx> Acesso em junho de 2016.

MATRIX - http://www.mapadaobra.com.br - Acessado em: Setembro 2014.

NETO, M. de F. F.; BERTOLI, S. R. Desempenho acústico de paredes de blocos e tijolos cerâmicos: uma comparação entre Brasil e Portugal. Porto Alegre, 2010.

NUNES,Heloá Palma -Estudo da aplicação do Drywall em edificação vertical. Disponível em:http://repositorio.roca.utfpr.edu.br/jspui/handle/1/6691 
REIS, Sonia. Drywall economiza $\mathbf{5 0 \%}$ do tempo na construção civil. Disponivel em: http://g1.globo.com/educacao/olimpiada-do-conhecimento/2012/noticia/2012/11/dry-walleconomiza-50-do-tempo-na-construcao-civil.html

SABBATINI, Fernando H. Tecnologia das construções de edifícios I. PCC-2435, 2003.

TAGLIABOA, Luís Claudio. Contribuição ao Estudo de Sistemas De Vedação Auto Portante. Disponível em: < http://www.sicablocos.com.br/tesedefendida.pdf> Acesso em 24 Agosto. 2018.

THOMAZ, Ercioet al. Código de Práticas no 1 - Alvenaria de vedação em blocos cerâmicos. IPT Instituto de pesquisas tecnológicas, São Paulo, 2009. 